\title{
Chronic Liver Diseases and Liver Cancer: State-of-the Art Progress in 2016
}

\author{
Masatoshi Kudo \\ Department of Gastroenterology and Hepatology, Kindai University Faculty of Medicine, Osaka-Sayama, Japan
}

The 13th Japan-Korea Liver Symposium was held in Kyoto on May 25-26, 2016, in conjunction with the 89th annual meeting of the Japan Society of Ultrasonics in Medicine, 12th Congress of Asian Federation of Societies for Ultrasound in Medicine and Biology, and 8th Congress of Asian Conference on Ultrasound Contrast Imaging.

Hagiwara et al. [1] evaluated the efficacy of direct-acting antiviral drugs for asunaprevir (ASV) and daclatasvir (DCV) for hepatitis $\mathrm{C}$ virus (HCV). The authors found that ASV/DCV combination therapy achieved sustained viral response (SVR) at 24 weeks in 106 of 120 (88\%) patients with HCV. They also stated that surveillance of hepatocellular carcinoma (HCC) is very important since risk of HCC development in patients who achieved SVR still exists.

Sugimoto et al. [2] evaluated the efficacy and safety of sofosbuvir plus rivavirin treatment for patients with chronic hepatitis $\mathrm{C}(\mathrm{CHC})$ genotype 2 . They reported that all patients (17/17) under sofosbuvir plus rivavirin treatment achieved end-of-treatment response. They also found that this combination therapy had an acceptable safety profile and resulted in no discontinuation of the treatment, irrespective of age or the effect of the polymorphisms of the inosine triphosphatase gene.

Nishida et al. [3] also evaluated the safety, tolerability and efficacy of sofosbuvir plus rivavirin therapy in elderly patients infected with HCV genotype 2 . They found that 37 of 41 patients achieved SVR 12 (90.2\%). They reported that the aged group ( $>75$ years) showed a lower

\section{KARGER}

E-Mail karger@karger.com

www.karger.com/ddi
SVR rate $(81.3 \%)$ at 12 weeks than the non-aged group ( $<75$ years) (96.0\%). They concluded that this combination therapy of sofosbuvir plus RBV is tolerable and beneficial not only in younger $(<75)$ patients but also in elderly (>75) patients.

$\mathrm{Wu}$ et al. [4] evaluated the two-dimensional shear wave elastography (2D SWE) as compared with real-time tissue elastography (RTE) for assessing liver fibrosis in patients with chronic hepatitis B (CHB). They concluded that 2D SWE obtained by Aixplorer US system (SuperSonic Imaging) was more accurate than RTE obtained by Ascendus (Hitachi) in the assessment of significant fibrosis and cirrhosis in patients with CHB. However, the measurement values and diagnostic performance obtained by 2D SWE are more affected by the inflammation fluctuations.

Yada et al. [5] evaluated the prospective risk analysis of HCC in patients with CHC by ultrasound strain elastography. Respective cumulative liver cancer incidence rates at 5 years in patients whose liver fibrosis index (LFI) determined by RTE of $<2.0,2-2.8$ and $>2.8$ were $0 \%, 19.9$ and $31.4 \%(\mathrm{p}=0.011)$ respectively. They concluded that measurement of LFI by strain imaging can successfully predict liver cancer risk in patients with chronic $\mathrm{HCV}$ infection.

Takita et al. [6] reported the epock-making therapy for polycystic liver disease, monoethanolamine oleate (EO) sclerotherapy. They concluded that EO infusion therapy achieves a fairly high treatment response in the volume reduction (99\%) and sustained shrinkage over long-term follow-up. Therefore, this is a breakthrough technique in
(C) 2016 S. Karger AG, Basel

0257-2753/16/0346-0617\$39.50/0
Masatoshi Kudo, MD, PhD

Department of Gastroenterology and Hepatology Kindai University Faculty of Medicine 377-2 Ohno-Higashi, Osaka-Sayama, Osaka 589-8511 (Japan) E-Mail m-kudo@med.kindai.ac.jp 
the treatment of polycystic liver disease as well as simple cyst and should be a standard of care for this disease.

Chishina et al. [7] evaluated the clinical effect of tolvap$\tan$, a vasopressin receptor antagonist, for refractory ascites in patients with decompensated liver cirrhosis. They concluded that the diuretic effect of tolvaptan may decrease in renal hypofunction patients. They also stated that continuation of tolvaptan administration is an option even though the early treatment effect is poor since its delayed effect was sometimes observed.

Kim et al. [8] evaluated the association of coffee intake and liver enzyme in Korean immigrants and Japanese. They found that coffee may inhibit hepatic damage caused by alcohol drinking and smoking both in Korean immigrants and Japanese.

Arizumi et al. [9] reported a validation study of Kinki criteria, a modified substaging system, in patients with intermediate stage HCC. They concluded that the performance of Kinki criteria is useful in determining the treatment strategy for HCC in the intermediate (BCLC B) stage.

Iwamoto et al. [10] evaluated the ability of Gd-EOB-DTPA enhanced MRI and contrast-enhanced ultrasound (CEUS) using sonazoid in the diagnosis of macroscopic type of 79 surgically resected HCCs. They concluded that the diagnostic performance for macroscopic classification of HCC of CEUS was comparable with that of Gd-EOB-DTPA enhanced MRI. Furthermore, they stated that the combination of the two modalities had a more accurate diagnostic performance.

Minami et al. [11] described US-US fusion imaging in radiofrequency ablation (RFA) for liver metastases. They concluded that US-US fusion imaging can contribute to RFA therapy with a safety margin since the image overlay of US-US fusion imaging allows the evaluation of the ablative margin three-dimensionally in real-time.

Kawasaki et al. [12] described the usefulness of CEUS as treatment guidance at RFA therapy for HCC [13-16] after transcatheter arterial chemoembolization (TACE) $[17,18]$. They stated the success rate of initial RFA guided by CEUS was $100 \%(22 / 22 \mathrm{HCCs})$ as compared with that guided by B mode US alone of $83.3 \%$ (15/18 HCCs).

Ogawa et al. [19] evaluated the usefulness of SYNAPSE VINCENT in the prediction of embolization area after TACE for HCC. They stated that this new technology, automatic prediction software of SYNAPSE VINCENT, has possibilities to reduce the amount of contrast medium, decrease radiation exposure and improve the therapeutic effect of TACE.

Nagai et al. [20] reported the role of tight junction protein ZO-1 (TJP1) and TWIST expression on postopera- tive survival of patients with HCC. Apparently, epithelial mesenchymal transition plays a critical role in cancer progression and metastasis. They stated that the upregulation of TWIST and the downregulation of TJP1 were significantly associated with sorter recurrence free survival as well as overall survival after surgical resection. They concluded that the low level of TJP1 and high level of TWIST expression are prognostic factors predicting the prevalence of HCC after surgical resection.

Nishida and Kudo [21] described the clinical significance of epigenetic alterations in human HCC and its association with genetic mutations. They stated that differentiation therapy is one of the potential approaches for HCC with advanced epigenetic alterations. On the other hand, a tumor changing an accumulation of genetic mutations would be good targets for immune reactions; thus, immune checkpoint blockade [22] should be effective for HCCs with genetic hypermutation.

Kudo [23] described the recent trend in the management of HCC, with special emphasis on treatment by regorafenib and immune checkpoint inhibitors. The author clearly states that regorafenib, as second-line systemic treatment, prolongs survival in patients with intermediate and advanced HCC who continued treatment with sorafenib [24-26]. Furthermore, immune checkpoint inhibitors are promising in the management of HCCs since clinical trials of PD-1 antibody, nivolumab, showed promising results in the treatment of advanced HCC.

Finally, I strongly believe that this special issue 'Chronic Liver Diseases and Liver Cancer: State-of-the Art Progress in 2016' will be beneficial and invaluable for all readers who specialize in understanding liver diseases including liver cancer.

\section{References}

1 Hagiwara S, Nishida N, Watanabe T, Sakurai T, Ida H, Minami Y, Takita M, Minami T, Iwanishi M, Chishina H, Ueshima K, Komeda Y, Arizumi T, Kudo M: Outcome of asunaprevir/daclatasvir combination therapy for chronic liver disease type C. Dig Dis 2016;34:620-626.

2 Sugimoto K, Kim SK, Kim SR, Kobayashi M, Kato A, Morimoto E, Imoto S, Kim CW, Tanaka Y, Kudo M, Yano Y, Hayashi Y: Efficacy and safety of sofosbuvir plus ribavirin treatment for patients with chronic hepatitis C genotype 2. Dig Dis 2016;34:627-631.

3 Nishida N, Kono M, Minami T, Chishina $\mathrm{H}$ Arizumi T, Takita M, Yada N, Ida H, Hagiwara S, Minami Y, Ueshima K, Sakurai T, Kudo M: Safety, tolerability, and efficacy of sofosbuvir plus ribavirin in elderly patients infected with hepatitis $C$ virus genotype 2 . Dig Dis 2016;34:632-639. 
4 Wu T, Wang P, Zhang T, Zheng J, Li SY, Zeng J, Kudo M, Zheng RQ: Comparison of twodimensional shear wave elastography and real-time tissue elastography for assessing liver fibrosis in chronic hepatitis B. Dig Dis 2016; 34:640-649.

5 Yada N, Sakurai T, Kudo M, Minami T, Arizumi T, Takita M, Hagiwara S, Ueshima $\mathrm{K}$, Ida H, Nishida N: Prospective risk analysis of hepatocellular carcinoma in patients with chronic hepatitis $\mathrm{C}$ by ultrasound strain elastography. Dig Dis 2016;34:650-653.

6 Takita M, Iwanishi M, Minami T, Kono M, Chishina H, Arizumi T, Yada N, Hagiwara S, Minami Y, Ida H, Ueshima K, Nishida N, Kudo M: Monoethanolamine oleate sclerotherapy for polycystic liver disease. Dig Dis 2016;34:654-658.

7 Chishina H, Hagiwara S, Nishida N, Ueshima K, Sakurai T, Ida H, Minami Y, Takita M, Kono M, Minami T, Iwanishi M, Umehara $Y$, Watanabe T, Komeda Y, Arizumi T, Kudo M: Clinical factors predicting the effect of tolvap$\tan$ for refractory ascites in patients with decompensated liver cirrhosis. Dig Dis 2016;34: 659-664.

$8 \mathrm{Kim} \mathrm{SK}$, Shin MH, Sugimoto K, Kim SR, Imoto S, Kim KI, Taniguchi M, Oh HK, Yano Y, Hayashi Y, Kudo M: Coffee intake and liver enzyme association in Korean immigrants and Japanese: a comprehensive cross-sectional study. Dig Dis 2016;34:665-670.

9 Arizumi T, Ueshima K, Iwanishi M, Minami T, Chishina H, Kono M, Takita M, Kitai S, Inoue T, Yada N, Hagiwara S, Minami Y, Ida H, Sakurai T, Kitano M, Nishida N, Kudo M: Validation of kinki criteria, a modified substaging system, in patients with intermediate stage hepatocellular carcinoma. Dig Dis 2016 34:671-678.

10 Iwamoto T, Imai $\mathrm{Y}$, Kogita S, Igura T, Sawai Y, Fukuda K, Yamaguchi Y, Matsumoto Y,
Nakahara M, Morimoto O, Seki Y, Ohashi H, Fujita N, Kudo M, Takehara T: Comparison of contrast-enhanced ultrasound and gadolinium-ethoxybenzyl-diethylenetriamine pentaacetic acid-enhanced MRI for the diagnosis of macroscopic type of hepatocellular carcinoma. Dig Dis 2016;34:679-686.

11 Minami Y, Minami T, Chishina H, Kono M, Arizumi T, Takita M, Yada N, Hagiwara S, Ida H, Ueshima K, Nishida N, KUdo M: US-US fusion imaging in radiofrequency ablation for liver metastases. Dig Dis 2016;34:687-691.

12 Kawasaki T, Hata KY, Kinoshita D, Takayama M, Okuda H, Mizuno S, KUdo M: Radiofrequency ablation guided by contrast-enhanced sonography versus B-mode sonography for hepatocellular carcinoma after transcatheter arterial chemoembolization. Dig Dis 2016;34:692-695.

13 Teng W, Liu KW, Lin CC, Jeng WJ, Chen WT, Sheen IS, Lin CY, Lin SM: Insufficient ablative margin determined by early computed tomography may predict the recurrence of hepatocellular carcinoma after radiofrequency ablation. Liver Cancer 2015;4:26-38.

14 Kudo M: Locoregional therapy for hepatocellular carcinoma. Liver Cancer 2015;4:163-164.

15 Kang TW, Rhim H: Recent advances in tumor ablation for hepatocellular carcinoma. Liver Cancer 2015;4:176-187.

16 Lencioni R, de Baere T, Martin RC, Nutting $\mathrm{CW}$, Narayanan G: Image-guided ablation of malignant liver tumors: recommendations for clinical validation of novel thermal and non-thermal technologies - a western perspective. Liver Cancer 2015;4:208-214.

17 Kudo M: Surveillance, diagnosis, treatment, and outcome of liver cancer in Japan. Liver Cancer 2015;4:39-50.

18 Tsurusaki M, Murakami T: Surgical and locoregional therapy of HCC: TACE. Liver Cancer 2015;4:165-175.
19 Ogawa C, Minami Y, Morita M, Noda A, Arasawa $S$, Izuta $M$, Kubo A, Matsunaka $T$, Tamaki N, Shibatouge M, Kudo M: Prediction of embolization area after conventional transcatheter arterial chemoembolization for hepatocellular carcinoma using SYNAPSE VINCENT. Dig Dis 2016;34:696-701.

20 Nagai T, Arao T, Nishio K, Matsumoto K, HagiwaraS, Sakurai T, Minami Y, Ida H, Ueshima K, Nishida N, Sakai K, Saijo N, Kudo K, Kaneda H, Tamura D, Aomatsu K, Kimura H, Fujita Y, Haji S, Kudo M: Impact of tight junction protein ZO-1 and TWIST expression on postoperative survival of patients with hepatocellular carcinoma. Dig Dis 2016;34:702-707.

21 Nishida N, Kudo M: Clinical significance of epigenetic alterations in human hepatocellular carcinoma and its association with genetic mutations. Dig Dis 2016;34:708-713.

22 Kudo M: Immune checkpoint blockade in hepatocellular carcinoma. Liver Cancer 2015;4: 201-207.

23 Kudo M: Recent trends in the management of hepatocellular carcinoma with special emphasis on treatment with regorafenib and immune checkpoint inhibitors. Dig Dis 2016;34: 714-730.

24 Arizumi T, Ueshima K, Minami T, Kono M, Chishina H, Takita M, Kitai S, Inoue T, Yada N, Hagiwara S, Minami Y, Sakurai T, Nishida N, Kudo M: Effectiveness of sorafenib in patients with transcatheter arterial chemoembolization (TACE) refractory and intermediate-stage hepatocellular carcinoma. Liver Cancer 2015;4:253-262.

25 Raoul JL, Gilabert M, Piana G: How to define transarterial chemoembolization failure or refractoriness: a European perspective. Liver Cancer 2014;3:119-124.

26 Peck-Radosavljevic M: Drug therapy for advanced-stage liver cancer. Liver Cancer 2014; 3:125-131. 